\title{
Applications of Manpower Levels for Business with various Recruitment Rates in the system through Stochastic Models
}

\author{
R, Arumugam, M. Rajathi
}

\begin{abstract}
Aim of the present study is to find the crisis in the steady state and steady state of probabilities with various circumstances which might be manpower, in irregular situations of complete accessibility and zero accessibility in the system of business, manpower along with recruitment. The various state has been conversed under the various assumptions that the transition from one state to another with different parameters.
\end{abstract}

Index Terms: Crisis rate, Markov chain, Steady state, Transition state.

\section{INTRODUCTION}

At the present time we find that work has transform into a purchasers' market just as dealer's commercial center. Any business which ordinarily keeps running on business base needs to keep just the ideal dimension of all assets basic to meet organization's obligation whenever, over the span of the labor and business isn't prohibition. This is spelt as in an organization might not have any desire to keep up labor more than what is alluring. In this manner, staffing and conservation are general and persevering in the greater part of the organizations now. Labor issues have been managed from multiple points of view as ahead of schedule as 1947 by Vajda [1] and others. In addition to Vassiliou [2] and Subramaniam [8] focused that manpower models with optimum promotion. Labor arranging models have been managed inside and out in Grinold and Marshal [3] and Barthlomew [4]. The strategies to wastages (release, renunciation and misfortune) and advancement forces which make the extents comparing to some favored arranging recommendations have been managed by Lesson [6]. For $\mathrm{n}$ unit remain by framework may allude to Ramanarayanan and Usha [5]. Chandrasekar et. al [7-10] deals with manpower model by using the confidence limits with various levels. Stochastic examination of labor levels influencing business with precarious enrollment rates by K. Harikumar et.al [11-13] markov Chain Model with Various States.

\section{Characteristics OF THE SySTEM}

There are three characteristics that's business, workforce (or) manpower) and accomplishment (or) recruitment are listening carefully in this area. The things could likewise be that the workforce could be barely offered totally accessible or business may vacillate between complete comforts to nil accessibility and in this way the achievement is full from the nil level. It goes off when the labor progresses toward becoming nil. This can be subsequently because of the advisors might get the trade together among the individuals. The probabilistic model interfacing the changes of probabilities with entirely unexpected states are perceived for exhibiting the esteem investigation. Numerical outlines are also given.

\section{ASSUMPTIONS}

1. Two dimensions of workforce explicitly labor is nothing and

labor is full.

2. Two dimensions of trade explicitly,

(i) Trade is full and exponentially dispersed with the framework ' $\mu$ '.

(ii) Nil dimension of trade with the framework ' $\lambda$ '.

3. While the workforce is filled and trade is filled it is

denoted by $\lambda_{111}$. It is changes to $\lambda_{112}$. The framework of the

allocation is $\lambda_{201}$ while the workforce is full and trade is zero and the same framework $\lambda_{101}$ changes to $\lambda_{202}$ with exponential time $\beta_{202}$.

4. The recruitment distribution with framework is $\mu_{001}$ while the

workforce is zero the trade is vanished. It changes to

$\mu_{002}$ with exponential time and the parameter $\alpha_{002}$.

5. Although the workforce turns into zero, the trade is vanished and turn into zero.

\section{METHODS OF THE STUDY}

The probabilistic method and the procedure $\mathrm{X}(\mathrm{t})$ depicting the framework is a persistent moment discrete stochastic process with eight point levels of workforce, trade and enlistment

$$
S=\left\{\left(\begin{array}{lll}
0 & 0 & 1
\end{array}\right),\left(\begin{array}{lll}
0 & 0 & 2
\end{array}\right),\left(\begin{array}{lll}
1 & 0 & 1
\end{array}\right),\left(\begin{array}{lll}
1 & 0 & 2
\end{array}\right),\left(\begin{array}{lll}
1 & 1 & 1
\end{array}\right),\left(\begin{array}{lll}
1 & 1 & 2
\end{array}\right),\right.
$$

(2 $\left.\left.\begin{array}{lll}2 & 1\end{array}\right),\left(\begin{array}{lll}2 & 0 & 2\end{array}\right)\right\}$------ (1)

\section{Published By:}

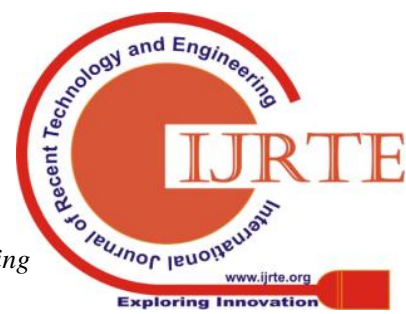


Where, the main co-ordinate alludes to non accessibility of labor. Second co-ordinate alludes to the trade; what's more the third co-ordinate shows selection level. The following matrix represents the various levels of steady state with eight point state space.

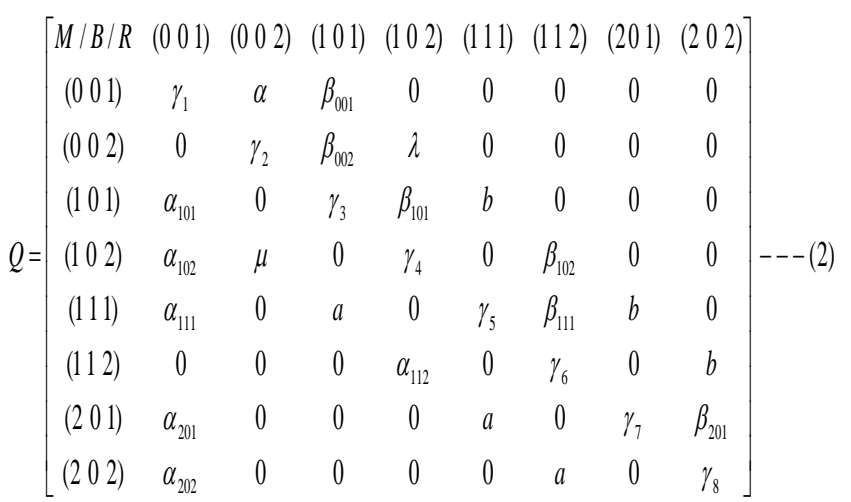

Where,

$$
\begin{aligned}
& \gamma_{1}=-\left(\beta_{001}+\alpha\right) \text {; } \\
& \gamma_{2}=-\left(\beta_{002}+\lambda\right) \\
& \gamma_{3}=-\left(\alpha_{101}+\beta_{101}+b\right) \text {; } \\
& \gamma_{4}=-\left(\alpha_{102}+\beta_{102}+\mu\right) \\
& \gamma_{5}=-\left(\alpha_{111}+a+b+\beta_{111}\right) \text {; } \\
& \gamma_{6}=-\left(\alpha_{112}+b\right) \\
& \gamma_{7}=-\left(\alpha_{201}+a+\beta_{201}\right) \text {; } \\
& \gamma_{8}=-\left(\alpha_{202}+a\right)
\end{aligned}
$$

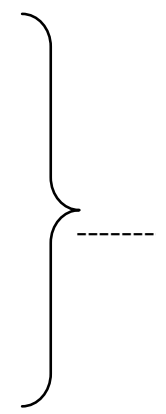

The occasions of change in labor, business and enrollment are given by

Let $\pi=\left[\pi_{001} \pi_{002} \pi_{101} \pi_{102} \pi_{111} \pi_{112} \pi_{201} \pi_{202}\right]$ be the unfaltering state likelihood vector of the $\mathrm{Q}$ matrix, at that point

$$
e \pi=1, \quad Q \pi=0
$$

From (4), we obtain

$$
\begin{gathered}
\pi_{001}=\frac{d_{1} \lambda}{z \sum_{i=0}^{2} d_{i}} ; \quad \pi_{002}=\frac{d_{2} \lambda}{z \sum_{i=0}^{2} d_{i}} ; \\
\pi_{101}=\frac{d_{1} \mu}{z \sum_{i=0}^{2} d_{i}} ; \quad \pi_{102}=\frac{d_{2} \mu}{z \sum_{i=0}^{2} d_{i}} ; \\
\pi_{111}=\frac{d_{1} \beta_{201}}{z \sum_{i=0}^{2} d_{i}} ; \quad \pi_{112}=\frac{d_{2} \beta_{201}}{z \sum_{i=0}^{2} d_{i}} \\
\pi_{201}=\frac{d_{1} \beta_{202}}{z \sum_{i=0}^{2} d_{i}} ; \quad \pi_{202}=\frac{d_{2} \beta_{202}}{z \sum_{i=0}^{2} d_{i}}
\end{gathered}
$$

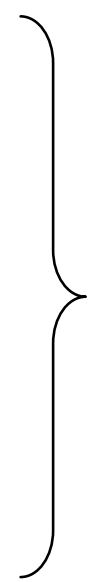

Where,

$$
\begin{aligned}
& d_{0}=\alpha_{001} \alpha_{201}+\alpha_{001} \alpha_{202}+\alpha_{201} \beta_{101}+\alpha_{202} \beta_{101}-\alpha_{202} \beta_{102} \\
& d_{1}=\alpha_{001} \alpha_{201}+\alpha_{001} \alpha_{202}+\alpha_{201} \beta_{102} \\
& d_{2}=\alpha_{001} \alpha_{202}+\alpha_{001} \alpha_{201}+\alpha_{201} \beta_{101} \\
& Z=[a+b] \text { and } \sum_{i=0}^{2} d_{i}=\left[d_{0}+d_{1}+d_{2}\right] .
\end{aligned}
$$

While labor is accessible business is full or nil. Labor is deficient or nil will prompt emergency state.

In this framework the emergency levels are $\left\{\begin{array}{lll}1 & 1 & 2\end{array}\right),\left(\begin{array}{lll}2 & 0 & 1\end{array}\right)$, ( $\left.\left.\begin{array}{lll}2 & 0 & 2\end{array}\right)\right\}$ and while zero trade or reasonable trade and the labor is reasonable likewise the enrollment is reasonable. Presently the change of emergency in the unfaltering level is mentioned below

$$
C_{\infty}=\alpha_{112} \pi_{112}+\alpha_{201} \pi_{201}+\alpha_{202} \pi_{202}
$$

Using steady state probabilities, we obtain the rate of crisis

$$
C_{\infty}=\frac{\lambda \mu}{Z \sum_{i=0}^{2} d_{i}}\left[\left(\alpha_{112} d_{2} \beta_{202}+\alpha_{201} d_{1} \beta_{202}+d_{2} \alpha_{202} \beta_{202}\right)\right]
$$

\section{ANALYSIS OF EIGHT POINT STATE SPACE}

\subsection{Eight point state space}

Case (i)

The relentless state probabilities and the rate of emergencies are estimated by utilizing the equations (6) and (7) separately, Assuming that, $\mathrm{a}=8, \mathrm{~b}=5, \lambda=6, \mu=3, \beta_{101}=4$,

$\beta_{102}=7, \beta_{201}=10, \beta_{202}=11, \alpha_{001}=7, \alpha_{112}=5$,

$\alpha_{201}=9, \alpha_{202}=4$,

We get $\pi_{001}=0.1795$

$\pi_{002}=0.1480, \quad \pi_{101}=0.0897$,

$\pi_{102}=0.0740, \quad \pi_{111}=0.2991, \pi_{112}=0.2467$

$\pi_{201}=0.3290$ and $\pi_{202}=0.2714$.

The crisis rate is 5.2803 .

Case (ii)

We assume that the value of $\mathrm{a}$ and $\mathrm{b}, \mathrm{a}=8, \mathrm{~b}=5, \lambda=6$, $\mu=3, \beta_{101}=4$, $\beta_{102}=7, \beta_{201}=10, \beta_{202}=11, \alpha_{001}=7, \alpha_{112}=5$, $\alpha_{201}=9, \alpha_{202}=4$.

Table: 1 Relationship among a, b and $C_{\infty}$

\begin{tabular}{|c|c|c|c|c|c|c|}
\hline $\mathrm{a}$ & 5 & 9 & 17 & 22 & 42 & 78 \\
\hline $\mathrm{b}$ & 5 & 8 & 15 & 29 & 45 & 82 \\
\hline C - infinity & 126.45 & 74.3824 & 39.5156 & 24.7941 & 14.5345 & 7.9031 \\
\hline
\end{tabular}




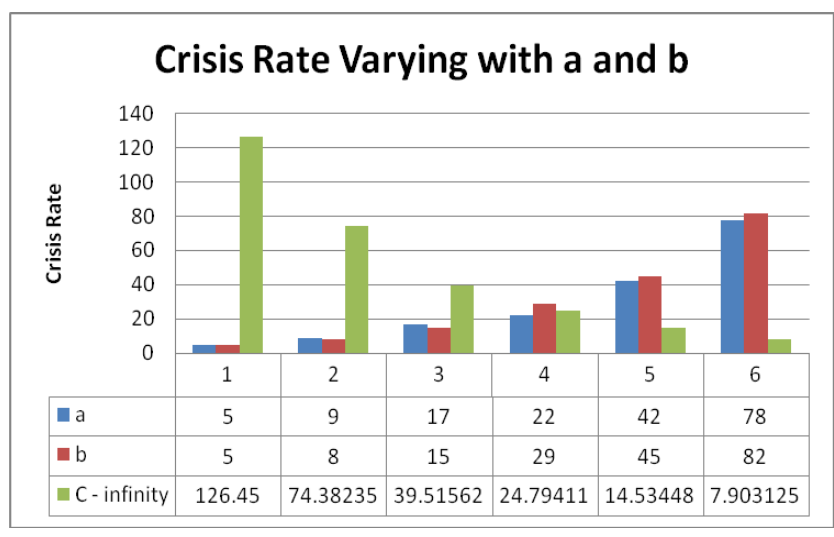

Figure: 1 Relationship among a, b and $C_{\infty}$

At the point when the estimations of an and $b$ increments and the relating emergency rate diminished.

The expenses of relentless state are dictated by utilizing the equation

$$
C_{i j k}=\left(c_{M P}^{i}+c_{B}^{j}+c_{R}{ }^{k}\right) \pi_{i j k}
$$

Where,

$c_{M P}{ }^{i}$ stands for cost of manpower at the states $\mathrm{i}=0$ or $\mathrm{i}=1$,

$c_{B}{ }^{j}$ stands for business cost at the states $\mathrm{j}=0$ or $\mathrm{j}=1$,

$c_{R}{ }^{k}$ stands for the departure or recruitment cost at the states

$\mathrm{k}=1$ or $\mathrm{k}=2$. We assume that the costs

$c_{M P}{ }^{0}=15, \quad c_{M P}{ }^{1}=20, c_{M P}{ }^{2}=10, c_{B}{ }^{0}=7$,

$c_{B}{ }^{1}=12, c_{R}{ }^{1}=5$ and $c_{R}{ }^{2}=13$

Table: 2 Relationship between steady state probability and steady state cost

\begin{tabular}{|l|c|c|c|c|}
\hline Steady state probability & $\pi_{001}=0.1795$ & $\pi_{002}=0.1480$ & $\pi_{101}=0.0897$ & $\pi_{102}=0.0740$ \\
\hline Steady state cost & 4.8195 & 5.18 & 2.8704 & 2.96 \\
\hline Steady state probability & $\pi_{111}=0.2991$ & $\pi_{112}=0.2466$ & $\pi_{201}=0.3290$ & $\pi_{202}=0.2714$ \\
\hline Steady state cost & 11.0667 & 11.097 & 7.238 & 8.142 \\
\hline
\end{tabular}

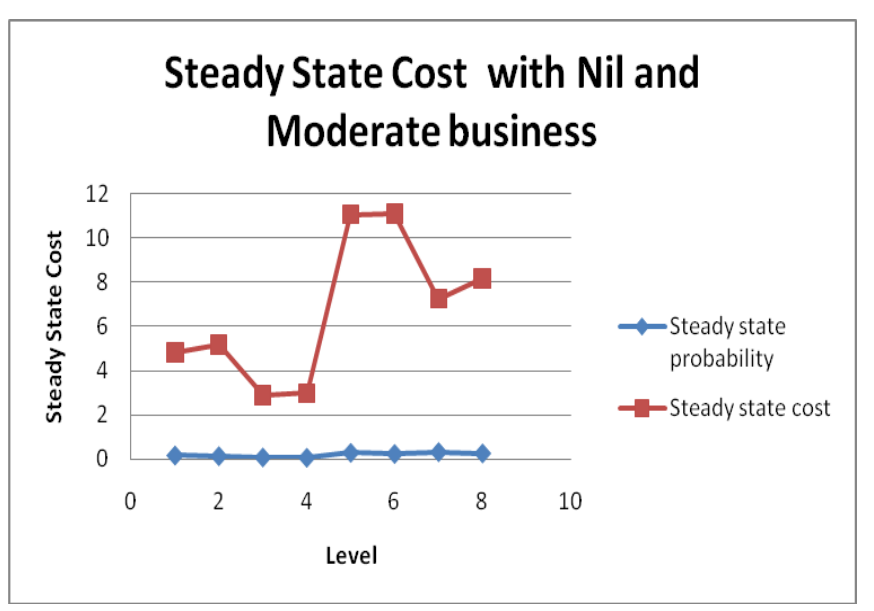

Figure: 2 Relationship between steady state cost and steady state probability

\section{CONCLUSION}

From the above idea we found that the unfaltering state cost increments, while there is full business additionally takeoff/enlistment rate increments. At the point when there is no matter of fact, the unfaltering state cost increments and the relating enlistment rate increments. Additionally it is seen that if there is full the same old thing and enrollment rate increments yet the relentless state cost diminishes.

\section{ACKNOWLEDGEMENT}

We thank our colleagues from Periyar Maniammai Institute of Science and Technology who provided insight and expertise that greatly assisted the research, although they may not agree with all of the interpretation of this paper. We thank Dr.K.Selvam, Head, Department of English, Periyar Maniammai Institute of Science and Technology for comments that greatly improved the article.

\section{REFERENCES}

[1] Vajda, "The stratified semi stationary population", Bio-Metrika, 34, 243-254, 1947.

[2] P.C.G. Vassiliou, "A higher order markovian model for prediction of wastage in manpower system", Operat. Res. Quart., 27, 1976.

[3] R.C. Grinold, K.T. Marshall, Manpower planning models, North Holl, New York, 1977.

[4] D.J. Barthlomew, Statistical technique for manpower planning, John Wiley, Chichester, 1979.

[5] R. Ramanarayanan, K. Usha, "n unit warm stand by system with Erlang failure and general repair and its dual", IEEE Trans. on Reliability, R-28, No. 2, 173-174, 1979.

[6] McClean, "Semi Markovian models in continuous time, J. Appl. Prob.", 16, 416-422, 1980.

[7] G.W. Lesson, "Wastage and promotion in desired manpower structures", J. Opl. Res. Soc., 33, 433-442, 1982.

[8] V. Subramanian, "Optimum promotion rate in a manpower models. International Journal of Management and Systems", 12(2), 79-184, 1996.

[9] Chandrasekar, Natrajan, "Two unit stand by system with confidence limits under steady state", 1997.

[10] K. Setlhare, "Modeling of an intermittently busy manpower system", In:Proceedings at the Conference held in Sept, 2006 at Gabarone, Botswana, 2007.

[11] K.Harikumar, R. Ramanarayanan, "Stochastic Analysis of Manpower Levels of Business with Varying Recruitment Rates", Applied Mathematical Sciences, 8(29), 1421-1428, 2014.

[12] C. Mohan, P.Selvaraju, "Stochastic Analysis of a Business with Varying Levels in Manpower and Business", International Journal of Applied Engineering Research, ISSN 0973-4562, 10(53), 2015.

[13] Arumugam R. Rajathi M, "Applications of manpower with various stages in Business using stochastic models, International Journal of Recent Trends in Engineering and Research", 3(1), 95-100, 2017. 


\section{AUTHORS PROFILE}

Dr. R Arumugam completed B.Sc Statistics in Periyar EVR College Trichy, Tamil Nadu during the year 1997-2000; M.Sc Statistics in Periyar EVR College Trichy, Tamil Nadu during the year 2000-2002; M.Phil in Statistics from Periyar EVR College Trichy, Tamil Nadu during the year 2002-2004 and Ph.D. in Statistics from Dravidian University, Andra Pradesh during 2009-2016. He is currently working as Assistant Professor in the Department of Mathematics, Periyar Maniammai Institute of Science and Technology (PMIST), Thanjavur, Tamilnadu since 2008. He is a life member of ISTE (Indian Society for Technical Education) since 2009. He has published more than 15 research papers in reputed national / international journals. His area of specialization is on Stochastic Process, Numerical Methods and Operations Research. He has 14 years of teaching experience. He has very familiar in the following papers like Mathematical Statistics - I, and II, Operations Research, Quantitative Techniques, Probability and Statistics, Probability and Queuing Theory, Numerical Methods, Engineering Mathematics - I, II and III, Business Statistics, Bio Statistics, Business Tools for Decision Making, Business Mathematics and Statistics and Research methodology. He has Guided MSc and M.Phil Students. He has attended conferences, seminars and workshops. Also, he has presented many papers in the conferences and seminars. Recently, he has organized one week workshop on Statistical Tools in Research Methodology.

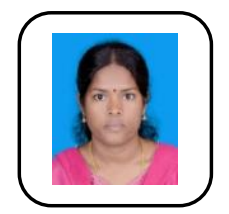

Mrs. M. Rajathi completed B.Sc. Computer Science in Holy Cross College, Trichy, Tamilnadu during the year 2003- 2006; M.Sc. Computer Science in Urumu Dhanalakshmi College, Trichy, Tamilnadu in the year 2006-2008; M.Phil Computer Science in Ponnaiyah Ramajeyam Institute of Science and Technology (PRIST) Thanjavur, Tamilnadu dring the year 2009 -2010; B.Ed Computer Science in Tamilnadu Teachers Education University, Chennai Tamilnadu dring the year 2010-2011 and M.A Education in Periyar University, Salem, Tamilnadu. She is currently working as Assistant Professor in Department of Education, Periyar Maniammai Institute of Science and Technology (PMIST), Thanjavur, Tamilnadu during 2015-2017. She has published more than 8 research papers in reputed national/ international journals. Her main research work focuses on Data Mining, Network Security, Simulation modeling and Cloud Computing. She has more than 5 years teaching experience in the various reputed institutions. She has very familiar in the following papers like $\mathrm{C}$ programming, $\mathrm{C}++$, Java programming language, Visual programming, Web technology, Operating system concept, SQL, MS Access, Data Structures and algorithm, Computer Graphics and Computer Networks, PHP, Software Engineering, Networking papers like ASP .Net, VB .Net. She has attended conferences, seminars and workshops. Also, she has presented papers in the conferences and seminars. 